\title{
Why Are Some Periods and Places So Astonishingly More Productive than Others?
}

\author{
Yong-Ha Kim
}

Editor in Chief, Archives of Plastic Surgery

Department of Plastic and Reconstructive Surgery, Yeungnam University College of Medicine, Daegu, Korea

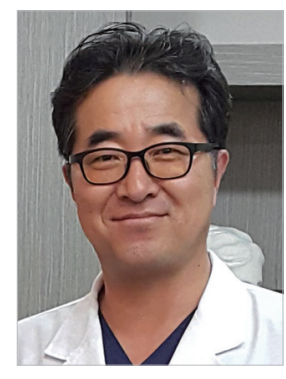

There is a saying that geniuses appear in flocks [1]. Socrates, Plato, and Aristotle in Greece (Classical Antiquity), Leonardo da Vinci, Michelangelo, and Donatello in Italy (Renaissance Period), Sir Humphrey Davy, Robert Owen, and Joseph Locke in England (Industrial Revolution), and Steve Jobs, Bill Gates, and Mike Zuckerberg in the United States (Information Age) are all excellent examples of this phenomenon. What could be the explanation behind this? Why did these geniuses appear around the world at these particular times? Why are some periods and societies much more productive? Some believe that the reason has to do with technological advances, changes in political and economic structures, increased interaction between different cultures, and the ability to glean information from historical documents and records. However, this cannot be the entire reason. Daniel Coyle wrote in his book Talent Code that to ascertain one's talents, man must enter into the furnace of success. While within this furnace, the person must identify possible skills and focus wholeheartedly on them through entering into 10,000 hours of study and practice. However, one must not forget to seek proper guidance and to stay motivated during those trying times. Coyle lastly pointed out that a huge number of talented people will appear in groups once the road to success is discovered [2].

When comparing plastic surgery in Korea to other countries, it is quite noticeable that there is an extraordinary amount of highly talented plastic surgeons. In 2015, The Washington Post described South Korea as the plastic surgery capital of the world [3]. The number of plastic surgeries performed in Korea has drastically increased, as surgeons are better able to guarantee their product and grant clienteles' requests. This has resulted in an environment where people are more receptive to the idea of receiving minor and major plastic surgery in Korea. In addition, the number of plastic surgery tourists has grown annually due to geopolitical factors. Among those plastic surgery tourists, the biggest markets are China followed by Japan, other East Asian countries, Russia, and varying Middle Eastern countries. Astonishingly, there has also been an uptick in customers from Europe and the United States.

Korean plastic surgery has developed and maintained systemic training programs modeled after the apprentice system used in the American medical system [4]. As per the 10,000 hours rule, Korean plastic surgeons finish four years-residency of learning and training in teaching hospital and continue their career as a fellowship at a university hospital or specialized clinic. Currently, Korean plastic surgery produces the world best results or similarly in the cosmetic and reconstructive fields. Due to the development of beauty surgery fields such as oculoplasty, rhinoplasty, and facial contouring, Korean plastic surgery has made great strides worldwide attracting foreign cosmetic surgery tourists. Moreover, it has created competitive results in reconstructive surgery such as microsurgery, breast reconstruction, and facial trauma surgery, as well as led to a plethora of world-renowned published research. As expressed above, numerous Korean surgeons are successfully realizing and utilizing their talents because of the aformentioned factors such as technological and intellectual advances and increased interaction between different 
cultures or nations. These factors have culminated in a manner that creates this ideal environment.

However, there is one more necessary component, and it is competition. There are more than 2,200 plastic surgeons in Korea, making it is the third largest after the United States and Brazil. When comparing the number of surgeons to the population, Korea has the most plastic surgeons. We estimate that there are ten times more cosmetic surgery related doctors when including non-specialists. Although the Korean plastic surgery market is large, the amount of competition is still fierce. Only skilled doctors who can continuously produce superior results are successful, and those who cannot are pushed out of the market [5]. In reality, this situation is not unique. Plastic surgeons in many different countries are experiencing the same atmosphere. As surgeons, we should continuously educate ourselves, undergo trial and error, and create new ideas. Being a plastic surgeon is a life long journey filled with learning. In order to better perfect our craft, we should learn from each other's failures and successes. Through documenting these experiences, we will be able to create a future filled with developed academic values.

The Archives of Plastic Surgery (APS), the official journal of The Korean Society of Plastic and Reconstructive Surgeons, provides a place where innovative ideas, talents, and information can be conveyed. APS has been rapidly spreading worldwide since the primary language was changed to English in 2012, and it was registered in PMC, Scopus, and Emerging Sources Citation Index [6]. As the impact factor value in 2015 is about 1.27, the Scopus value is Source Normalized Impact per Paper 1.05, Impact per Publication 1.239, SCImago Journal Rank 7.11, APS marked above $50 \%$ in world surgical journal fields and ranked second place in Asia's surgical journal fields. APS wants to contribute to humanity through its intellectual legacy. We also want to be the main forum for communication among plastic surgery scholars and clinicians. Lastly, I hope that more and more geniuses will successfully express their talents, enthusiastically participate, competitively debate, and be modeled by our discussions into better surgeons. For these people, APS will gladly be a medium of communication.

\section{ORCID}

Yong-Ha Kim http://orcid.org/0000-0002-1804-9086

\section{REFERENCES}

1. Bank D. The problem of excess genius [Internet]. Chicago, IL: Newsletter of the Classification Society of North America; 1997 [cited 2015 May 16]. Available from: http://www. monad.com/sdg/Journal/genius.html.

2. Coyle D. The talent code: greatness isn't born: it's grown, here's how. New York: Bantam Books; 2009.

3. Swanson A. Wonkblog: stunning photos show why S. Korea is the plastic surgery capital of the world [Internet]. Washington, DC: The Washington Post; c2015 [cited 2015 May 16]. Available from: http://www.washingtonpost.com/news/ wonkblog/wp/2015/05/16/stunning-photos-show-whysouth-korea-is-the-plastic-surgery-capital-of-the-world/.

4. Kwon ST. Plastic surgery training: a privilege and honor. Arch Plast Surg 2015;42:265-6.

5. Cho BC. Tradition and Future of the Korean Society of Plastic and Reconstructive Surgeons. Arch Plast Surg 2016;43:1-2.

6. Kim YH. The Current Position of Archives of Plastic Surgery and Its Future. Arch Plast Surg 2015;42:387-90.

Correspondence: Yong-Ha Kim

Department of Plastic and Reconstructive Surgery, Yeungnam University College of Medicine

170 Hyeonchung-ro, Nam-gu, Daegu 42415, Korea

Tel: +82-53-620-3481, Fax: +82-53-626-0705, E-mail: kimyon@ynu.ac.kr

No potential conflict of interest relevant to this article was reported.

Received: 31 Aug 2016• Revised: 31 Aug $2016 \bullet$ Accepted: 31 Aug 2016

pISSN: 2234-6163・ elSSN: 2234-6171

http://dx.doi.org/10.5999/aps.2016.43.5.391 • Arch Plast Surg 2016:43:391-392 